Original Article

\title{
COMPARISON OF BODY MASS INDEX WITH MODIFIED SUBJECTIVE GLOBAL ASSESSMENT FOR DETECTION OF MALNUTRITION AMONG PATIENTS UNDER MAINTENANCE HEMODIALYSIS: A MULTI-CENTER CROSS-SECTIONAL STUDY
}

\author{
Mohammad Syfur Rahman ${ }^{1}$, Mohammad Farhadul Haque ${ }^{2}$, Tayeba Sultana ${ }^{3}$, Tahera Sultana ${ }^{4}$, Syed \\ Asif Ul Alam ${ }^{5}$
}

\begin{abstract}
Background: Patients under maintenance hemodialysis are at increased risk of malnutrition, causing from multitude of factors. Present study aims to assess the prevalence of malnutrition among maintenance hemodialysis patients using both modified subjective global assessment score and body mass index, compare them and assess the sensitivity and specificity of body mass index for detecting malnutrition, along with determining a new cutoff value for BMI that better represent the maintenance hemodialysis patient's nutritional status.

Methods: This was a cross-sectional study conducted in the hemodialysis unit of Bangabandhu Sheikh Mujib Medical University, Sir Salimullah Medical College Mitford Hospital, BIRDEM General Hospital and National Institute of Kidney Diseases \& Urology; among 80 adult CKD patients who were on regular ( $\geq 2$ sessions per week) maintenance hemodialysis for more than 3 months without any acute infection, during the period of July 2016 to June 2017. Nutritional assessment was done for each patient using modified SGA score along with BMI. Sensitivity analysis of WHO recommended cutoff value for BMI was done among the study population using modified SGA score as gold standard test for detection of malnutrition among the respondents. ROC curve was used to estimate the best fitting cutoff value of BMI that showed highest sensitivity, specificity and accuracy for detracting malnutrition among maintenance hemodialysis patients.
\end{abstract}

Results: The study participants were predominantly male (66.3\%) and from age group 45 to 59 years (36.3\%). Modified SGA score detected $90.0 \%$ of the study population as malnourished. WHO recommended $18.5 \mathrm{~kg} / \mathrm{m}^{2}$ cutoff value was also used to detect malnutrition among study population and $13.8 \%$ were found to be malnourished, with a sensitivity and specificity of $12.5 \%$ and $75.0 \%$ respectively. Accuracy was found to be $18.8 \%$. Using ROC curve, 23.1 $\mathrm{kg} / \mathrm{m}^{2}$ was found to be the best fitting cutoff value of BMI for the study population to detect malnutrition. With a sensitivity of $47.2 \%$, specificity of $37.5 \%$ and accuracy of $46.3 \%$.

Conclusion: BMI showed low sensitivity for detecting malnutrition among patients under maintenance hemodialysis, compared to modified SGA score and should be avoided as a screening tool, but $23.1 \mathrm{~kg} / \mathrm{m}^{2}$ cutoff value for BMI showed potential to be used as an easy to use and quick tool for detecting malnutrition among such patients. Further study with larger sample size could shed more light on this.

JOPSOM 2021; 40(1):14-21

https://doi.org/10.3329/jopsom.v40i1.56686

Keywords: Sensitivity, Specificity, Accuracy, BMI, Modified SGA Score.

1. Assistant Professor, Department of Nephrology, Sylhet M.A.G Osmani Medical College, Sylhet. E-mail: syfur27@gmail.com

2. Assistant Director Hospital, Shaheed Monsur Ali Medical College Hospital, Dhaka - 1215, Bangladesh. Email: farhadulhaque@gmail.com

3. Medical Officer, Department of Feto-Maternal Medicine, Bangabandhu Sheikh Mujib Medical University, Dhaka.E-mail: sultanatayeba@gmail.com

4. Medical Officer, Department of Radiology \& Imaging, Bangabandhu Sheikh Mujib Medical University, Dhaka.E-mail: sumi.ssmc @ gmail.com

5. Assistant Professor, Department of Orthopedics, Faridpur Medical College, Faridpur. E-mail: drisrafil47@gmail.com

*Correspondence: Mohammad Farhadul Haque, E-mail: farhadulhaque@gmail.com 


\section{INTRODUCTION}

Patients under maintenance hemodialysis often suffer from malnutrition, leading to an increased incidence of mortality and morbidity ${ }^{1,2}$. The process of hemodialysis removes nutrients and promotes protein catabolism. It also induces anorexia caused by uremic state, altered taste sensation, concurrent illness, emotional distress, impaired ability to procure, prepare or mechanically digest foods, unpalatable prescribed diets and the catabolic response to superimposed illness ${ }^{3}$. Patients under maintenance hemodialysis are the most vulnerable to malnutrition and are in constant need of nutritional support. Maintaining proper nutritional status can drastically improve outcome of the treatment leading to reduced duration and cost of treatment ${ }^{4-9}$. While treatment outcome has been found to be directly dependent on the nutritional status of the patients, screening for malnutrition is often ignored and over looked in many dialysis centers ${ }^{10-13}$.

There have been several different scales proven to be effective in screening for malnutrition, but not all are easily assessable in hospital environment. Among them subjective global assessment has shown the most accuracy for detecting malnutrition among end stage renal disease patients, specially patients under maintenance hemodialysis ${ }^{14-16}$. Subjective global assessment (SGA) score is a well-validated screening tool recommended by the American Society for Parenteral and Enteral Nutrition (ASPEN) for nutritional screening ${ }^{17-20}$, determined by medical history on seven items and clinical findings on four items. Using components of conventional SGA, in 1999, Kalantar-Zadeh et al presented a version of the SGA that was originally referred to as modified quantitative $\mathrm{SGA}^{1}$. This fully quantitative version of SGA used the 7 original SGA components and created a quantitative 5-point scale with 1 as normal and 5 as very severe malnutrition. The final score was the total sum of all 7 components. Total range was from 7 (normal) to 35 (severely malnourished). SGA is mostly examiner dependent, fully quantitative, performed in few minutes, reproducible and definitely determines the nutritional status of hemodialysis patients. SGA gives a global score of protein energy nutritional status. Disadvantages of this method include the fact that visceral protein levels are not included in the assessment; it is focused on nutrient intake and body composition ${ }^{18}$. It seems that modified SGA is superior to conventional SGA and more suitable to detect the changing trend of nutritional status ${ }^{21,22}$.

On the other hand, anthropometric parameter such as body mass index (BMI) has been widely in use as metrics for nutritional status ${ }^{23}$. Although, its practicality and accuracy in assessing malnutrition among hemodialysis patients have not been convincing ${ }^{24}$. In Bangladesh, there is a high prevalence of malnutrition among patients with end stage renal disease (ESRD) as the calorie and protein intake of these patients are poor ${ }^{25}$. Modified subjective global assessment (SGA) has been in use in Bangladesh as a simple and dynamic tool to assess malnutrition, but for faster screening in a hospital setup, BMI classification could be used.

This study was carried out to assess the prevalence of malnutrition among maintenance hemodialysis patients using both modified subjective global score and body mass index, compare them and assess the sensitivity and specificity of body mass index for detecting malnutrition, along with determining a new cutoff value for BMI that better represent the maintenance hemodialysis patient's nutritional status.

\section{METHODS}

This was a cross-sectional study conducted in the hemodialysis unit of Bangabandhu Sheikh Mujib Medical University (BSMMU), Sir Salimullah Medical College Mitford Hospital (SSMCMH), BIRDEM General Hospital and National Institute of Kidney Diseases \& Urology (NIKDU); all situated in Dhaka, during the period of July 2016 to June 2017. Study was conducted among adult CKD patients who were on regular ( $\geq 2$ sessions per week) maintenance hemodialysis for more than 3 months without any acute infection. As per selection criteria, 80 patients were enrolled for the study. Patients were fully briefed regarding the study before the enrollment and written consent were collected from every participant during enrollment. Ethical approval was collected from the local ethical committee of respective institute.

Data were collected through face-to-face interview using a pre-tested data collection sheet. The relevant socio-demographic data along with anthropometric and nutritional status data of the patients were collected and recorded. Computer based statistical analysis were carried out with appropriate techniques and systems. Quantitative data were expressed as mean and standard deviation and qualitative data were expressed as frequency distribution and percentage. Statistical analysis was performed by using Statistical Packages for Social Sciences (SPSS® version 22) for Windows $®$.

From the anthropometric data, body mass index (BMI) was calculated for all the respondents and were classified as per WHO guideline ${ }^{26}$. Researchers performed all anthropometric measurements 
immediately after a dialysis session. All participants were considered normohydrated. If patients were overhydrated anthropometric measurements were postponed. Height and body weight were measured in light clothing using standard instruments. As per WHO guideline, BMI $<18.5 \mathrm{~kg} / \mathrm{m}^{2}$ was classified as malnourished and BMI $\geq 18.5 \mathrm{~kg} / \mathrm{m}^{2}$ was classified as without malnutrition. Nutritional status of the respondents was evaluated using modified SGA score. Modified SGA score was proposed in 1999 based on SGA score ${ }^{1}$. The SGA score was based on 5 components of a medical history (i.e., weight change, dietary intake, gastrointestinal symptoms, functional capacity, metabolic demands in view of underlying disease state) and 2 components of a brief physical examination (signs of fat and muscle wasting, nutrition-associated alterations in fluid balance). The patient is then assigned a rating of well nourished, moderately malnourished or severely malnourished ${ }^{24}$. In this study subjective global assessment was performed by using 7 point modified SGA scale.

For the purpose of this study, sensitivity analysis of BMA classification was done among the study population using modified SGA score as gold standard for detection of malnutrition among patients on maintenance hemodialysis. (Figure 1). Accuracy of the test was measured along with predictive values and likelihood ratios ${ }^{27,28}$. Predictive ratio were used to estimate trust ability of the test ${ }^{29}$.

\begin{tabular}{|c|c|c|c|}
\hline \multicolumn{2}{|c|}{} & \multicolumn{2}{|c|}{$\begin{array}{c}\text { Nutritional status } \\
\text { according to } \\
\text { modified SGA } \\
\text { score }\end{array}$} \\
\cline { 3 - 4 } & \multicolumn{2}{|c|}{$\begin{array}{c}\text { Positive } \\
\text { Negative }\end{array}$} \\
\hline \multirow{2}{*}{$\begin{array}{c}\text { Test } \\
\text { status }\end{array}$} & Positive & a & b \\
\cline { 2 - 4 } & Negative & c & d \\
\hline
\end{tabular}

Figure 1: Sensitivity analysis

\section{Sensitivity and Specificity}

According to Trevethan ${ }^{27}$, sensitivity is the proportion of people with a condition who are correctly identified by a screening test as indeed having that condition and specificity is the proportion of people without a condition who are correctly identified by a screening test as indeed not having the condition. Sensitivity = $a /(a+c)$. Specificity $=d /(d+b)$.

\section{Accuracy}

Accuracy of a test is its ability to differentiate the patient and healthy cases correctly. It is the proportion of true positive and true negative in all evaluated cases 30. Accuracy $=(a+d) /(a+b+c+d)$

\section{Predictive Values}

Positive predictive value (PPV) is the probability that people with a positive screening test result indeed do have the condition of interest and negative predictive value (NPV) is the probability that people with a negative screening test result indeed do not have the condition of interest ${ }^{27}$.

Positive predictive value $(P P V)=a /(a+b)$

Negative predictive value $(N P V)=d /(c+d)$

\section{RESULTS}

Among the study population, $38.8 \%$ were from over 60 years aged, followed by $36.3 \%$ from $45-59$ years of age group (Table I). Study population was predominantly male $(66.3 \%)$.

Table I: Descriptive statistics of the study population

\begin{tabular}{|c|c|c|c|}
\hline \multicolumn{2}{|l|}{ Criteria } & $\begin{array}{l}\text { Frequency } \\
\mathbf{N}=\mathbf{8 0}\end{array}$ & $\begin{array}{l}\text { Percentage } \\
(\%)\end{array}$ \\
\hline \multicolumn{4}{|c|}{ Age in years } \\
\hline & $18-29$ & 8 & 10.0 \\
\hline & $30-44$ & 12 & 15.0 \\
\hline & $45-59$ & 29 & 36.3 \\
\hline & $\geq 60$ & 31 & 38.8 \\
\hline \multicolumn{4}{|l|}{ Sex } \\
\hline & Male & 53 & 66.3 \\
\hline & Female & 27 & 33.8 \\
\hline \multicolumn{2}{|l|}{ Total } & 80 & $100 \%$ \\
\hline
\end{tabular}

Study population was classified based on their nutritional status using both modified SGA score and BMI (Table II). According to modified SGA score, $90 \%$ of the respondents were malnourished. According to BMI, $13.8 \%$ were malnourished. WHO recommended $18.5 \mathrm{~kg} / \mathrm{m}^{2}$ was used as cutoff for BMI 26 . 
Table II: Results of modified SGA score and BMI

\begin{tabular}{|c|c|c|}
\hline Test & Frequency $(\mathrm{n}=80)$ & Percentage $(\%)$ \\
\hline \multicolumn{3}{|l|}{ Modified SGA Score } \\
\hline Malnourished $(\geq 8)$ & 72 & 90.0 \\
\hline Well-nourished $(<8)$ & 8 & 10.0 \\
\hline \multicolumn{3}{|l|}{ BMI (Cutoff at $18.5 \mathrm{~kg} / \mathrm{m}^{2}$ ) } \\
\hline Malnourished $\left(<18.5 \mathrm{~kg} / \mathrm{m}^{2}\right)$ & 11 & 13.8 \\
\hline Well-nourished $\left(\geq 18.5 \mathrm{~kg} / \mathrm{m}^{2}\right)$ & 69 & 86.3 \\
\hline \multicolumn{3}{|l|}{ BMI (Cutoff at $23.1 \mathrm{~kg} / \mathrm{m}^{2}$ ) } \\
\hline Malnourished $\left(<23.1 \mathrm{~kg} / \mathrm{m}^{2}\right)$ & 39 & 48.8 \\
\hline Well-nourished $\left(\geq 23.1 \mathrm{~kg} / \mathrm{m}^{2}\right)$ & 41 & 51.2 \\
\hline Total & 80 & $100 \%$ \\
\hline
\end{tabular}

Using modified SGA score as gold standard, sensitivity and specificity of BMI $\left(18.5 \mathrm{~kg} / \mathrm{m}^{2}\right.$ as cutoff value) for detecting malnutrition among patients under maintenance hemodialysis was calculated (Table III). Sensitivity was found to be
$12.5 \%$ and specificity was found to be $75.0 \%$ for BMI (Table IV). Accuracy was found to be $18.8 \%$. Positive predictive value (PPV) and Negative predictive value (NPV) were found to be $81.8 \%$ and $8.7 \%$ respectively.

Table III: Sensitivity Analysis of BMI compared to modified SGA score

\begin{tabular}{|l|l|l|l|}
\hline \multicolumn{2}{|c|}{} & \multicolumn{2}{|l|}{$\begin{array}{l}\text { Nutritional status according to modified SGA } \\
\text { score }\end{array}$} \\
\cline { 3 - 4 } \multicolumn{2}{|c|}{} & Malnourished & $\begin{array}{l}\text { Without } \\
\text { Malnutrition }\end{array}$ \\
\hline \multirow{2}{*}{$\begin{array}{l}\text { BMI using } 18.5 \mathrm{~kg} / \mathrm{m}^{2} \text { as cutoff } \\
\text { value }\end{array}$} & Malnourished & $9(12.5 \%)$ & $2(25.0 \%)$ \\
\cline { 2 - 4 } $\begin{array}{l}\text { BMI using } 23.1 \mathrm{~kg} / \mathrm{m}^{2} \text { as cutoff } \\
\text { value }\end{array}$ & Well-nourished & $63(78.8 \%)$ & $6(75.0 \%)$ \\
\cline { 2 - 4 } \begin{tabular}{l} 
Total \\
\cline { 3 - 4 }
\end{tabular} & Well-nourished & $34(42.5 \%)$ & $5(62.5 \%)$ \\
\hline
\end{tabular}

ROC curve was done to determine the best fitting cutoff value of BMI for the study population against the gold standard, modified SGA score (Figure 2). Based on younder index, BMI $23.1 \mathrm{~kg} / \mathrm{m}^{2}$ was found to be the cutoff value with maximum accuracy. Using $23.1 \mathrm{~kg} / \mathrm{m}^{2}$ as cutoff value for BMI, $48.8 \%$ of the study population were found to be malnourished (Table II). Using modified SGA score as gold standard, sensitivity and specificity of BMI $\left(23.1 \mathrm{~kg} / \mathrm{m}^{2}\right.$ as cutoff value) for detecting malnutrition among patients under maintenance hemodialysis was calculated. Sensitivity was found to be $47.2 \%$ and specificity was found to be $37.5 \%$, with an accuracy of 46.3\%. Positive predictive value (PPV) and Negative predictive value (NPV) were found to be $87.2 \%$ and $7.3 \%$ respectively.

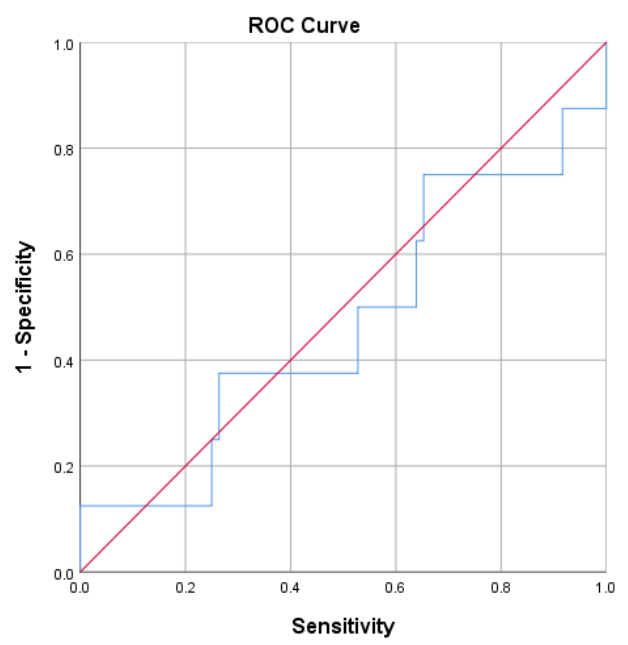


Figure 2: ROC Curve showing sensitivity and specificity of BMI to accurately identify malnutrition among study population, compared to modified SGA score used as gold standard.

Table IV: Estimated values of test parameters

\begin{tabular}{|c|c|c|}
\hline Tests parameters & $\begin{array}{c}\text { BMI using } \\
\mathbf{1 8 . 5} \mathbf{~ k g / \mathbf { m } ^ { 2 }} \text { as } \\
\text { cutoff value }\end{array}$ & $\begin{array}{c}\text { BMI using } \\
\mathbf{2 3 . 1} \mathbf{~ k g} / \mathbf{m}^{\mathbf{2}} \\
\text { as cutoff } \\
\text { value }\end{array}$ \\
\hline Sensitivity & $12.5 \%$ & $47.2 \%$ \\
\hline Specificity & $75.0 \%$ & $37.5 \%$ \\
\hline Accuracy & $18.8 \%$ & $46.3 \%$ \\
\hline $\begin{array}{c}\text { Positive predictive } \\
\text { value (PPV) }\end{array}$ & $81.8 \%$ & $87.2 \%$ \\
\hline $\begin{array}{c}\text { Negative predictive } \\
\text { value (NPV) }\end{array}$ & $8.7 \%$ & $7.3 \%$ \\
\hline
\end{tabular}

\section{DISCUSSIONS}

Respondents in present study was predominantly male (66.3\%) and majority (38.8\%) were from over 60 years of age. Similar findings have been shown in previous studies among patients under hemodialysis where male were $62.9 \%$ and $60.9 \%$ were above 60 years of age ${ }^{31}$. Respondents were classified into malnourished and well-nourished groups and according to modified SGA score, $90 \%$ of the respondents were malnourished. This finding is consistent with another study from India ${ }^{32}$, where using modified SGA, malnutrition rate was $91 \%$ among 66 patients undergoing hemodialysis. Present study used modified SGA score as gold standard for assessing nutritional status, since modified SGA is a reliable prognostic indicator for malnutrition. Previous studies have shown that modified SGA not only determines the nutritional status, but also predicts the likelihood of complications from malnutrition ${ }^{10,33-35}$. In present study, using WHO recommended cutoff value of $18.5 \mathrm{~kg} / \mathrm{m}^{2}$ for BMI, $13.8 \%$ were classified as malnourished. This result is consistent with nutritional assessment conducted among elderly population, where $>10 \%$ had malnutrition with a BMI of 18.5 $\mathrm{kg} / \mathrm{m}^{236}$.

WHO recommended cutoff value for BMI was evaluated for sensitivity and specificity for detecting malnutrition among patients under maintenance hemodialysis. Sensitivity was found to be $12.5 \%$ and specificity was found to be $75.0 \%$, with an accuracy of only $18.8 \%$. This indicates the cutoff value of 18.5 $\mathrm{kg} / \mathrm{m}^{2}$ could accurately detect the nutritional status of only $18.8 \%$ of the respondents. These findings suggest that the WHO recommended cutoff value of 18.5 $\mathrm{kg} / \mathrm{m}^{2}$ is not suitable to detect malnutrition among patients under maintenance hemodialysis. This result is consistent with previous studies, where malnutrition and obesity prevalence in maintenance hemodialysis patients were simultaneously assessed ${ }^{37,38}$. These studies have shown an overlap between patients with malnutrition and those with obesity, indicating a problem with nutritional assessment methodologies, further supporting the fact that BMI may not be a reliable indicator for nutritional assessment among maintenance hemodialysis patients ${ }^{39-45}$, but BMI is relatively easy, inexpensive and less time consuming to measure than modified SGA score ${ }^{23,46}$.

So, in order to develop a new cutoff value for BMI that could detect malnutrition among patients under maintenance hemodialysis, ROC curve was used. A cutoff value of $23.1 \mathrm{~kg} / \mathrm{m}^{2}$ was found to have shown the maximum accuracy (46.3\%) in detecting the nutritional status of the respondents with a sensitivity of $47.2 \%$ and specificity of $37.5 \%$. This higher sensitivity means that at the cutoff value of $23.1 \mathrm{~kg} / \mathrm{m}^{2}$, BMI could detect more patients with malnutrition than WHO recommended $18.5 \mathrm{~kg} / \mathrm{m}^{2}$. Now if we have increased the cutoff value even more, it would have increased the sensitivity, but it would reduce the specificity even lower to the point that accuracy of the test becomes substantially lower.

\section{STRENGTH}

Modified SGA score was used as gold standard to identify the nutritional status of the respondents. Sensitivity, specificity, predictive values and accuracy of BMI were compared against modified SGA score, increasing the validity and precision of the study. Also, study was conducted among respondents from multiple centers, generating results more acceptable and accurate than studies conducted in one center.

\section{CONCLUSION}

Due to the design of the study, each sample was interviewed once, doings subsequent follow ups over an extended period of time would have given us more data on the predictive capabilities of BMI classification on developing malnutrition among patients under maintenance hemodialysis. But solely based on the findings of this study, BMI based nutritional assessment doesn't appear to be a reliable method for detecting malnutrition among patients under maintenance hemodialysis, although if needed, a BMI value of $23.1 \mathrm{~kg} / \mathrm{m}^{2}$ could be used as a easy to use marker for detecting malnutrition among maintenance hemodialysis patients, until proper assessment is possible. A small sample size of 80 was used for present study, future studies with bigger sample size is highly recommended for a more 
accurate and reliable cutoff value of BMI for maintenance hemodialysis patients.

\section{Acknowledgement}

Authors would like to thank all the respondents for their co-operation.

\section{REFERENCES}

1. Kalantar-Zadeh K, Kleiner M, Dunne E, Lee GH, Luft FC. A modified quantitative subjective global assessment of nutrition for dialysis patients. Nephrol Dial Transplant Off Publ Eur Dial Transpl Assoc - Eur Ren Assoc. 1999;14(7):1732-1738. doi:10.1093/ndt/14.7.1732

2. Ghorbani A, Hayati F, Karandish M, Sabzali S. The prevalence of malnutrition in hemodialysis patients Implication for health policy/practice/research/medical education. $J$ Ren Inj Prev J Ren Inj Prev. 2020;9(2):x-x. doi:10.15171/jrip.2020.xx

3. Must A, Dallal GE, Dietz WH. Reference data for obesity: 85th and 95th percentiles of body mass index (wt/ht2) and triceps skinfold thickness. Am J Clin Nutr. 1991;53(4):839-846. doi:10.1093/ajen/53.4.839

4. Neumayer LA, Smout RJ, Horn HG, Horn SD. Early and sufficient feeding reduces length of stay and charges in surgical patients. J Surg Res. 2001;95(1):73-77. doi:10.1006/jsre.2000.6047

5. Heys SD, Walker LG, Smith I, Eremin O. Enteral nutritional supplementation with key nutrients in patients with critical illness and cancer: a meta-analysis of randomized controlled clinical trials. Ann Surg. 1999;229(4):467-477. doi:10.1097/00000658-199904000-00004

6. Potter J, Langhorne P, Roberts M. Routine protein energy supplementation in adults: systematic review. BMJ. 1998;317(7157):495501. doi:10.1136/bmj.317.7157.495

7. Smedley F, Bowling T, James M, et al. Randomized clinical trial of the effects of preoperative and postoperative oral nutritional supplements on clinical course and cost of care. Br J Surg. 2004;91(8):983-990. doi:10.1002/bjs.4578

8. Lewis SJ, Egger M, Sylvester PA, Thomas S. Early enteral feeding versus "nil by mouth" after gastrointestinal surgery: systematic review and meta-analysis of controlled trials. BMJ. 2001;323(7316):773-776. doi:10.1136/bmj.323.7316.773
9. Omari AM, Omari LS, Dagash HH, Sweileh WM, Natour N, Zyoud SH. Assessment of nutritional status in the maintenance of haemodialysis patients: a cross-sectional study from Palestine. BMC Nephrol. 2019;20(1):92. doi:10.1186/s12882-019-1288-z

10. Detsky AS, McLaughlin JR, Baker JP, et al. What is subjective global assessment of nutritional status? JPEN J Parenter Enteral Nutr. 1987;11(1):8-13. doi:10.1177/014860718701100108

11. Kalantar-Zadeh K, Kopple JD. Relative contributions of nutrition and inflammation to clinical outcome in dialysis patients. Am J kidney Dis Off J Natl Kidney Found. 2001;38(6):1343-1350. doi:10.1053/ajkd.2001.29250

12. Lawson JA, Lazarus R, Kelly JJ. Prevalence and prognostic significance of malnutrition in chronic renal insufficiency. J Ren Nutr Off $J$ Counc Ren Nutr Natl Kidney Found. 2001;11(1):16-22. doi:10.1016/s10512276(01)85914-8

13. Jones JM. The methodology of nutritional screening and assessment tools. J Hum Nutr Diet Off J Br Diet Assoc. 2002;15(1):55-59. doi:10.1046/j.1365-277x.2002.00327.x

14. Oksa H, Ahonen K, Pasternack A, Marnela KM. Malnutrition in hemodialysis patients. Scand $J$ Urol Nephrol. 1991;25(2):157-161. doi:10.3109/00365599109024551

15. Guidelines for the use of parenteral and enteral nutrition in adult and pediatric patients. JPEN $J$ Parenter Enteral Nutr. 2002;26(1 Suppl):1SA138SA.

16. Kondrup J, Allison SP, Elia M, Vellas B, Plauth $M$. ESPEN guidelines for nutrition screening 2002. Clin Nutr. 2003;22(4):415-421. doi:10.1016/s0261-5614(03)00098-0

17. Detsky AS, Baker JP, Mendelson RA, Wolman SL, Wesson DE, Jeejeebhoy KN. Evaluating the accuracy of nutritional assessment techniques applied to hospitalized patients: methodology and comparisons. JPEN J Parenter Enteral Nutr. 1984;8(2):153-159. doi:10.1177/0148607184008002153

18. Persson C, Sjödén PO, Glimelius B. The Swedish version of the patient-generated subjective global assessment of nutritional status: gastrointestinal vs urological cancers. Clin Nutr. 1999;18(2):71-77. doi:10.1016/s0261- 


\section{4(99)80054-5}

19. Julien JP, Combe C, Lasseur C. Subjective global assessment of nutrition a useful diagnostic tool for nurses? EDTNA-ERCA J. 2001;27(4):193-196. doi:10.1111/j.17556686.2001.tb00177.x

20. Mueller C, Compher C, Ellen DM. A.S.P.E.N. clinical guidelines: Nutrition screening, assessment, and intervention in adults. $J$ Parenter Enter Nutr. 2011;35(1):16-24. doi:10.1177/0148607110389335

21. Wühl E, Haffner D, Tönshoff B, Mehls O. Predictors of growth response to $\mathrm{rhGH}$ in short children before and after renal transplantation. German Study Group for Growth Hormone Treatment in Chronic Renal Failure. Kidney Int Suppl. 1993;43:S76-82.

22. Broyer M, Kleinknecht C, Loirat C, MartiHenneberg C, Roy MP. Growth in children treated with long-term hemodialysis. J Pediatr. 1974;84(5):642-649. doi:10.1016/s00223476(74)80003-X

23. Claris-Appiani A, Ardissino GL, Daccò V, Funari C, Terzi F. Catch-up growth in children with chronic renal failure treated with long-term enteral nutrition. JPEN J Parenter Enteral Nutr. 1995;19(3):175-178. doi:10.1177/0148607195019003175

24. Detsky AS, Mclaughlin J, Baker JP, et al. What is subjective global assessment of nutritional status? J Parenter Enter Nutr. 1987;11(1):8-13. doi:10.1177/014860718701100108

25. Reza HM, Shuvo S Das, Ahmad T. Assessing the prevalence of malnutrition in chronic kidney disease patients undergoing hemodialysis in Kushtia District, Bangladesh. Nutr Food Sci. 2018;48(1):150-164. doi:10.1108/NFS-05-20170103

26. WHO. Body Mass Index.

27. Trevethan R. Sensitivity, Specificity, and Predictive Values: Foundations, Pliabilities, and Pitfalls in Research and Practice. Front Public Heal. 2017;5:307. doi:10.3389/fpubh.2017.00307

28. McGee S. Simplifying likelihood ratios. J Gen Intern Med. 2002;17(8):647-650. doi:10.1046/j.1525-1497.2002.10750.x

29. Grunau G, Linn S. Commentary: Sensitivity, Specificity, and Predictive Values: Foundations, Pliabilities, and Pitfalls in Research and Practice.
Front Public Heal. 2018;6:307. doi:10.3389/fpubh.2018.00256

30. Baratloo A, Hosseini M, Negida A, El Ashal G. Part 1: Simple Definition and Calculation of Accuracy, Sensitivity and Specificity. Emerg (Tehran, Iran). 2015;3(2):48-49. doi:10.22037/emergency.v3i2.8154

31. Ishiwatari A, Yamamoto S, Fukuma S, Hasegawa T, Wakai S, Nangaku M. Changes in Quality of Life in Older Hemodialysis Patients: A Cohort Study on Dialysis Outcomes and Practice Patterns. Am J Nephrol. 2020;51(8):650-658. doi:10.1159/000509309

32. Janardhan V, Soundararajan P, Rani N, et al. Prediction of malnutrition using modified subjective global assessment-dialysis malnutrition score in patients on hemodialysis. Indian J Pharm Sci. 2011;73(1):38-45. doi:10.4103/0250-474X.89755

33. Enia G, Sicuso C, Alati G, Zoccali C. Subjective global assessment of nutrition in dialysis patients. Nephrol Dial Transplant. 1993;8(10):1094-1098. http://europepmc.org/abstract/MED/8272222

34. Baker JP, Detsky AS, Wesson DE, et al. Nutritional assessment: a comparison of clinical judgement and objective measurements. $N$ Engl J Med. 1982;306(16):969-972. doi:10.1056/NEJM198204223061606

35. Jeejeebhoy KN. Nutritional assessment. Nutrition. 2000;16(7-8):585-590. doi:10.1016/s0899-9007(00)00243-4

36. Skeie E, Tangvik RJ, Nymo LS, Harthug S, Lassen K, Viste A. Weight loss and BMI criteria in GLIM's definition of malnutrition is associated with postoperative complications following abdominal resections - Results from a National Quality Registry. Clin Nutr. 2020;39(5):1593-1599. doi:10.1016/j.clnu.2019.07.003

37. Honda H, Qureshi AR, Axelsson J, et al. Obese sarcopenia in patients with end-stage renal disease is associated with inflammation and increased mortality. Am J Clin Nutr. 2007;86(3):633-638. doi:10.1093/ajen/86.3.633

38. Cordeiro AC, Qureshi AR, Stenvinkel P, et al. Abdominal fat deposition is associated with increased inflammation, protein-energy wasting and worse outcome in patients undergoing haemodialysis. Nephrol Dial Transplant. 2010;25(2):562-568. doi:10.1093/ndt/gfp492 
39. Koefoed M, Kromann CB, Juliussen SR, et al. Nutritional status of maintenance dialysis patients: Low lean body mass index and obesity are common, protein-energy wasting is uncommon. PLoS One. 2016;11(2). doi:10.1371/journal.pone.0150012

40. Torun D, Micozkadioglu H, Torun N, Ozelsancak R, Sezer S, Adam FU. Increased Body Mass Index Is Not a Reliable Marker of Good Nutrition in Hemodialysis Patients. Fatma Nurhan Ozdemir \& Mehmet Haberal. 2007;29(4):487-493. doi:10.1080/08860220701274959

41. Yuste C, Abad S, Vega A, et al. Assessment of nutritional status in haemodialysis patients. Nefrologia. 2013;33(2):243-249. doi:10.3265/Nefrologia.pre2013.Jan.11670

42. Valtuille R, Casos ME, Fernandez EA, Guinsburg A, Marelli C. Nutritional Markers and Body Composition in Hemodialysis Patients. Int Sch Res Not. 2015;2015:1-7. doi:10.1155/2015/695263

43. Bashardoust B, Gavami M, Maleki N, Doustkami H, Habibzadeh S. Mortality and nutritional status in patients undergoing hemodialysis. Shiraz E Med J. 2015;16(2). doi:10.17795/semj20076

44. Kittiskulnam P, Eiam-Ong S. Body Composition and Its Clinical Outcome in Maintenance Hemodialysis Patients. In: Aspects in Dialysis. InTech; 2018. doi:10.5772/intechopen.70353

45. Hassanin IA, Hassanein H, Elmenshawy P, et al. Malnutrition Score and Body Mass Index as Nutritional Screening Tools for Hemodialysis Patients. Clin Nutr ESPEN. Published online February 9, 2021. doi:10.1016/j.clnesp.2021.01.044

46. Janardhan V, Soundararajan P, Rani N, et al. Prediction of malnutrition using modified subjective global assessment-dialysis malnutrition score in patients on hemodialysis. Indian J Pharm Sci. 2011;73(1):38-45. doi:10.4103/0250-474X.89755 